\title{
Aspek Psikologi Pendelegasian Manajemen dan Manajemen Biaya Pabrik Roti "Yes" di UPK PIK Pulo Gadung Jakarta Timur
}

\author{
Hanif Hanif'1), Mulyani Mulyani2), Supriyanto Karya ${ }^{3)}$, Morryessa Brandinie ${ }^{4)}$ \\ 12) Program Studi Akuntansi, Institut Bisnis dan Informatika Kwik Kian Gie \\ hanif.ismail@kwikkiangie.ac.id \\ mulyani@kwikkiangie.ac.id \\ 3) Program Studi Sistem Informasi Institut Bisnis dan Informatika Kwik Kian Gie \\ supriyanto.karya@kwikkiangie.ac.id \\ 4) Program Studi IImu Administrasi Bisnis Institut Bisnis dan Informatika Kwik Kian Gie \\ morryessa_brandinie@kwikkiangie.ac.id
}

\begin{abstract}
ABSTRAK
Tujuan kegiatan pengabdian kepada masyarakat ini adalah untuk melakukan pendampingan dalam rangka membantu pelaku usaha menyusun strategi guna menyelesaikan masalah dalam pengelolaan bisnis. Pendekatan yang digunakan adalah observasi, wawancara dan diskusi dengan pendiri/pemilik usaha. Tempat kegiatan adalah di salah satu unit bisnis di bawah Unit Pengelola Kegiatan Pusat Industri Kecil (PIK), yaitu Pabrik Kue "Yes". Pelaksana kegiatan berhasil menggali beberapa masalah di unit bisnis tersebut, yang terkait dengan pembukuan, pendelegasian kerja dan perancangan sistem pengendaliannya, pemanfaatan manajemen biaya seperti perhitungan unit cost, pengendalian biaya dan analisis break event point, dan kebijakan bagi hasil. Pelaksana kegiatan juga memberikan solusi yang bersifat mampu-laksana yang dapat dieksekusi oleh perusahaan.

Kata-kata Kunci: Pembukuan, Pendelegasian Kerja, Sistem Pengendalian, Unit Cost,

Break Event Point
\end{abstract}

\begin{abstract}
The purpose of this program is to provide assistance in order to help businesses to solve their problems in business management. The approach used is observation, interview and discussion with the business founder/owner. The place is in the one of the business unit under the Unit Pengelola Kegiatan Pusat Industri Kecil (PIK), namely "Yes" Cake Factory. The team managed and explored several problems in the business unit, which are related to book-keeping, work delegation and the control system planning, utilization of cost management such as unit cost calculations, cost control and break event point analysis, and profit-sharing policy. The team also provides a doable solution that can be implemented by the company.
\end{abstract}

Keywords: Book-keeping, Work Delegation, Control System, Unit Cost, Break Event Point

\section{PENDAHULUAN}

Beberapa kendala dalam pendelegasian manajemen dalam bisnis keluarga, khususnya yang bermula dari usaha rumah tangga yang masuk dalam kelompok Usaha Mikro Kecil dan Menengah (UMKM) dapat diuraikan sebagai berikut: (a) bisnis keluargaUMKM biasanya dimulai dari "nol", artinya usaha yang benar-benar berangkat dari semangat juang untuk memperbaiki kehidupan. Salah satu cirinya adalah semuanya dikerjakan sendiri oleh pendiri/pemilik usaha, tanpa karyawan karena meminimalkan biaya dan risiko; (b) pengelolaan bisnis dilakukan secara otodidak; (c) energi pengelola dicurahkan untuk mencari pasar, dengan fokus utama mencari pelanggan; (d) akibatnya segi administrasi umumnya terabaikan. 
Ketika volume usaha meningkat, maka beragam kebutuhan pekerjaan mulai muncul. Pada saat seperti ini dibutuhkan karyawan yang dapat membantu pelaksanaan pekerjaan dan pendelegasian pekerjaan sudah harus dimulai. Pendelegasian pekerjaan membutuhkan keahlian tersendiri, yakni keahlian dalam mencapai tujuan perusahaan melalui tangan-tangan orang lain, yang merupakan konsep hakiki dari manajemen (Anthony, Govindarajan \& Dearden, 2007). Namun, meskipun teori manajemen mengatakan demikian, dalam pelaksanaannya tidaklah mudah. Pekerjaan yang sudah terbiasa dikerjakan sendiri, bahkan sudah mendarahdaging dalam diri pendiri, kini harus didelegasikan kepada orang lain. Untuk itulah mengetahui bagaimana pendelegasian manajemen dapat terlaksana di lapangan dan mengetahu kendala-kendala dalam mengimplementasikannya menjadi sangat penting.

Terkait dengan hal tersebut, permasalahan yang saat ini dihadapi oleh Pabrik Kue "Yes", yang terletak di kawasan Pulo Gadung, adalah (a) ada keengganan pendiri/pemilik usaha untuk melaksanakan inti dari manajemen, yakni pendelegasian pekerjaan yang diiringi dengan sistem pengendalian manjemen yang memadai, termasuk pendelegasian pembukuan; (b) belum dilakukannya pengendalian biaya kecuali mengandalkan kemampuan kontrol langsung dari pendiri/pemilik usaha; (c) manajemen Pabrik Kue "Yes" belum dapat memanfaatkan secara maksimal kehadiran sosial media untuk pengembangan bisnis, terutama dalam kegiatan marketing.

Guna membantu terselenggaranya manajemen bisnis yang lebih baik, sesuai dengan kaidah pengelollan bisnis sebagaimana mestinya, maka kegiatan pengabdian kepada masyarakat ini dilaksanakan oleh para dosen dari beberapa progran studi di lingkungan Institut Bisnis dan Informatika Kwik Kian Gie pada Pabrik Kue "Yes". Kegiatan ini dilaksanakan pada Semester Genap 2017/2018.

\section{METODE PELAKSANAAN}

Kegiatan dimulai dengan melakukan observasi pada Pabrik Kue "Yes", dan dilanjutkan dengan wawancara dan diskusi dengan pendiri/pemilik usaha. Observasi dimaksudkan untuk mendapatkan gambaran atas masalah pendelegasian wewenang dan praktik manajemen perusahaan pada saat ini. Wawancara dilakukan untuk mendapatkan informasi langsung dari pendiri/pemilik sekaligus mengkonfirmasi temuan dari hasil observasi. Diskusi dilakukan untuk menyusun solusi dan memperoleh konfirmasi kesiapan pendiri/pemilik atas rumusan solusi yang akan diusulkan oleh tim pelaksana.

\section{HASIL DAN PEMBAHASAN}

Pabrik Kue "Yes" didirikan pada tahun 1998 oleh seorang wanita yang saat ini berusia 50 tahun. Berada pada kondisi krisis ekonomi yang sangat sulit, wanita tersebut 
berupaya untuk keluar dari tekanan ekonomi. Berbekal kemauan yang keras, modal yang terbatas dan hobi yang ditekuninya, wanita tersebut memulai bisnisnya dengan membuat kue (roti). Dua puluh tahun kemudian, bisnisnya telah berkembang dan kini mempekerjakan 50 orang karyawan. Wanita ini menguasai $A$ sampai $Z$ seluruh aspek manajemen pada perusahaannya, meliputi aspek produksi, pemasaran, operasi dan keuangan. Meskipun tidak memiliki latar belakang pendidikan bisnis, karena telah menekuni bisnisnya selama 20 tahun maka dia mengetahui persis seluruh kegiatan di perusahaannya. Kemampuannya belajar sendiri (otodidak) dan kemauannya untuk menerima masukan dari pihak lain, menjadikan perusahaannya tumbuh dan berkembang hingga saat ini. Namun pada beberapa tahun terakhir, pertumbuhannya melambat seiring dengan terbatasnya daya kendali yang dimilikinya. Hambatan lainnya adalah adanya trauma psikologis yang dialami oleh pendiri/pemilik karena pernah gagal mengembangkan inovasi dan ditipu oleh karyawannya. Oleh karenanya, diperlukan bantuan pihak lain untuk mengatasi hambatan tersebut.

Pada saat ini Pabrik Kue "Yes" memiliki dua pabrik, masing-masing berlokasi di dalam dan di luar Kawasan PIK Pulo Gadung. Lokasi di luar Kawasan PIK Pulo Gadung menyatu dengan toko kue. Lokasi ini terdiri dari $200 \mathrm{~m} 2$ pabrik, 50m2 toko kue, dan sebuah ruang tamu yang dapat menampung 10 orang. Toko kue dirancang dengan menggunakan dinding kaca agar lebih mudah dilihat oleh pelanggan dan calon pelanggan. Ruang tamu dipersiapkan untuk menerima supplier, calon pelanggan, agen penjual, dan tamu lainnya.

Kunci sukses dari Pabrik Kue "yes" adalah terus menerus berinovasi dalam produk dan layanan kepada pelanggan. Pemilik menyadari sepenuhnya bahwa di dalam bisnis kue, menjaga rasa, menciptakan variasi produk dan harga produk yang bersaing adalah kunci dalam memenangkan persaingan. Terkait dengan harga produk, pendiri telah sadar biaya (cost consciousness) dan menyadari pentingnya pengelolaan biaya (cost management). Namun hingga saat ini pengelolaan biaya belum dilakukan sebagaimana mestinya. Pembukuan belum dilakukan sebagaimana mestinya. Perusahaan juga belum menerapkan prinsip-prinsip akuntansi dalam costing, hanya berdasarkan memory accounting.

Belum ada karyawan yang bekerja untuk hal ini. Alasannya adalah, “...menghadirkan orang yang ahli itu mahal, biaya lagi, biaya lagi...sehingga nanti akan membengkakkan pengeluaran biaya sehingga berdampak pada harga jual...”. Keengganan mempekerjakan karyawan di bagian pembukuan disebabkan oleh trauma psikologis yang pernah dialaminya ketika mengembangkan website perusahaan. Karyawan yang dipekerjakannya melakukan praktek penipuan dengan mencantumkan nomor rekening bukan milik perusahaan untuk menerima pembayaran dari pelanggan. Ketika pelanggan telah mentransfer uang, barang segera dikirim. Namun uang pembayaran tidak kunjung masuk ke rekening perusahaan. 
Pemikil terlibat pada seluruh jenis pekerjaan. Hal ini terungkap dalam pernyataannya, “.....Semua pekerjaan saya tangani sendiri... ya...semuanya, produksi, pemasaran, dan keuangan...lagi pula pendelegasian tidak mudah untuk saya, dulu ada orang yang saya rekrut untuk membantu di bidang IT untuk membuat web, tetapi hanya sebagai konsultan,... akhirnya tidak jalan, saya sendiri karena kemampuan saya kurang di bidang web, jadi tidak dapat secara langsung mengarahkan...hasilnya ketergantungan saya sangat tinggi pada orang itu, sementara setiap ada permasalahan web harus kontak orang itu,...lama-lama, karena kerjaan ini sambilan untuk orang itu, .... Akhirnya web tidak jalan, ...dan ada penipuan pula, ....jadi saya trauma merekrut orang-orang pintar itu... "

Trauma psikologis tersebut mengandung kelebihan dan sekaligus kekurangan. Kelebihannya adalah pengalaman jatuh bangun dalam menjalankan usaha adalah modal besar untuk mengawal dan mengembangkan usaha. Hal ini merupakan salah satu faktor yang menyebabkan Pabrik Kue "Yes" dapat bertahan dan berkembang dalam lingkungan bisnis yang sangat dinamis. Sedangkan kelemahannya adalah menjadikan pendiri/pemilik usaha sulit dan tidak mudah percaya dengan hal-hal baru yang membutuhkan keahlian tertentu, misalnya pentingnya pembukuan dan pemanfaatan teknologi informasi untuk mendukung kegiatan bisnis. Termasuk kepercayaan kepada anak-anaknya sendiri.

Dengan kemampuannya sendiri, pendiri/pemilik usaha terus berinovasi. Salah satunya adalah menerapkan sistem beli putus dengan agen penjualnya. Terbukti sistem ini mampu meningkatkan volume penjualan. Di samping itu, perusahaan juga sudah mulai aktif mengikuti pameran kuliner yang diselenggarakan oleh badan-badan pemerintah. Tentu saja harapannya adalah meningkatnya volume bisnis perusahaan. Peningkatan volume bisnis ini tentu saja harus diikuti dengan perubahan pola pikir (mindset) dari pendiri/pemillik. Pengelolaan bisnis secara profesional dengan mengikuti kaidah manajemen yang standar harus mulai diterapkan.

Melihat perkembangan tersebut, maka melalui diskusi dengan pendiri/pemilik usaha, tim pelaksanaka kegiatan ini telah menyusun solusi yang doable yang dapat diimplementasikan segera namun bertahap. Solusi tersebut adalah:

(a) Mulai menerapkan pembukuan sesuai dengan kaidah yang berlaku. Hal ini akan membantu perusahaan untuk melakukan penganggaran, menghitung unit cost, menetapkan harga jual yang tepat, serta dapat menjadi dasar dalam pengambilan keputusan bisnis lainnya.

(b) mulai melakukan analisis unit cost agar harga jual yang ditetapkan mampu bersaing di pasar. 
(c) Mulai melakukan analisa break even point untuk meningkatkan efisiensi produksi dan menambah kapasitas produksi jika diperlukan penambahan volume produksi dan perluasan pasar.

(d) Mulai menggunakan teknologi informasi untuk mendukung kegiatan operasional dan kegiatan pemasaran.

Mengenai tertib administrasi dan semua hal yang terkait dengan akuntansi (pembukuan, analsis unit cost, analisis break even point, pengendalian biaya, dan penetapan harga kompetitif) sudah harus mulai didelegasikan kepada ahlinya. Untuk menghemat biaya, dapat dimulai dengan bekerjasama Institut Bisnis dan Informatika Kwik Kian Gie (IBI-KKG) melalui program mahasiswa magang dengan didampingi oleh dosen pembimbing magang. Mahasiswa Program Studi Akuntansi telah dibekali kemampuan untuk melakukan hal-hal tersebut dengan mengadopsi berbagai analisis untuk kepentingan internal manajemen perusahaan (Blocher, Stout, Juras, \& Cokins, 2013; Hilton, 2008; Hansen \& Mowen, 2005). Penerapan prinsip-prinsip tersebut akan menghasilkan keputusan dan kebijakan yang dapat meningkatan produktivitas perusahaan (Hanif, Rakhman \& Nurkholis, 2018).

Pendiri/pemilik usaha sebagai entrepreneur sudah melakukan tindakan yang tepat dengan menerapkan konsep beli putus untuk mendongkrak penjualan. Konsep bagi-hasil sesungguhnya juga dapat diterapkan karena didalamnya mengandung konsep berbagi risiko. Konsep ini merangsang para agen penjual untuk bekerja keras menghasilkan pendapatan, sehingga mampu memotivasi para pekerja untuk produktif karena penghasilan yang akan diterimanya tergantung pada volume penjualan (Hanif, Ludigdo, Rahman, \& Baridwan, 2015; Hanif, 2015a; Hanif, 2015b; Hanif, 2017; Hanif, et. al., 2018).

Teknologi informasi dapat diadopsi untuk mendukung kegiatan operasional dan kegiatan pemasaran. Pemasaran dengan memanfaatkan sosial media, tidak hanya melalui WEB, tetapi juga Instagram, Twiiter, Line, WA Group, dan lain-lain dapat mulai diterapkan. Untuk memulainya kerjasama dengan IBI-KKG dapat dilakukan juga, namun kali ini dengan mahasiswa Program Studi Teknik Informatika dan atau Program Studi Sistem Informasi.

\section{KESIMPULAN}

Di tengah perkembangan usahanya, Pabrik Kue "Yes" masih menghadapi hambatan. Hambatan tersebut adalah (a) pemilik belum memiliki keberanian untuk melaksanakan inti manajemen yakin pendelegasian kerja dengan diiringi sistem pengendalian yang memadai termasuk di bidang pembukuan; (b) belum dilakukan tertib administrasi dalam pengendalian biaya, perhitungan unit cost dan perhitungan break event point; (c) ada trauma psikologis dalam upaya pemanfaatan teknologi informasi. 
Saran yang disampaikan untuk mengatasi hambatan bisnis dan mengantisipasi pertumbuhan bisnis di masa yang akan datang adalah (a) segera melakukan pendelegasian wewenang, yang dapat dimulai dengan mahasiswa magang di bawah bimbingan dosen pembimbing magang; (b) segera melaksanakan proses administrasi perusahaan sebagaimana mestinya; (3) segera menggunakan teknologi informasi dan sosial media untuk mendukung kegiatan operasional dan kegiatan pemasaran.

Penerapan saran-saran tersebut dapat dilakukan secara bertahap dengan pendampingan dari IBI-KKG, baik oleh dosen maupun mahasiswa magang. Dengan demikian kepercayaan diri dari pendiri/pemilik usaha dapat ditumbuhkembangkan. Diperlukan kerjasama dan saling percaya diantara kedua pihak agar hasilnya dapat dirasakan secara nyata.

\section{REFERENSI}

Anthony, R. N., Govindarajan, V., \& Dearden, J. (2007). Management Control Systems (Vol.12). New York: McGraw-Hill.

Blocher, E. J., Stout, D. E., Juras, P. E., \& Cokins, G. (2013). Cost Management: A Strategic Emphasis (7th Ed.). New York: McGraw-Hill.

Hanif, Ludigdo, U., Rahman, A. F., \& Baridwan, Z. (2015). Akuntansi Bagi-Hasil Sistem Mato:Etnografi Bisnis Restoran Padang. Jakarta: Mitra Wacana Media.

Hanif. (2015a). Introducing Mato Based Profit-Sharing Accounting and its Synergy with Cooperative and Sharia. Procedia - Social and Behavioral Sciences, 211, 1223-1230. https://doi.org/http://dx.doi.org/10.1016/j.sbspro.2015.11.163

Hanif. (2015b). Management Control System Design: An Interpretive Ethnography. Procedia - Social and Behavioral Sciences, 211, 119-126. https://doi.org/http://dx.doi.org/10.1016/i.sbspro.2015.11.018

Hanif. (2017). (Re)konstruksi Akuntansi Keuangan Bagi Hasil Sistem Mato. Jurnal Akuntansi Multiparadigma, 8(2), 1-15. http://jamal.ub.ac.id/index.php/jamal/article/view/505

Hanif, Rakhman, A., Nurkholis, M. (2018). New Productivity Concept Based on Local Wisdom: Lessons from Indonesia. Journal of Management and Marketing Review. https://papers.ssrn.com/sol3/papers.cfm?abstract id=3267325

Hansen, D. R. \& Mowen, M. M. (2005). Management Accounting (7th Ed.). Singapore: Thomson South-Western.

Hilton, R W. (2008). Managerial Accounting: Creating Value in a Dynamics Environment. New York: McGraw-Hill; 
Academics in Action Journal

Volume 1, Number 1, 2019, 20-26

\section{LAMPIRAN}

Foto Kegiatan
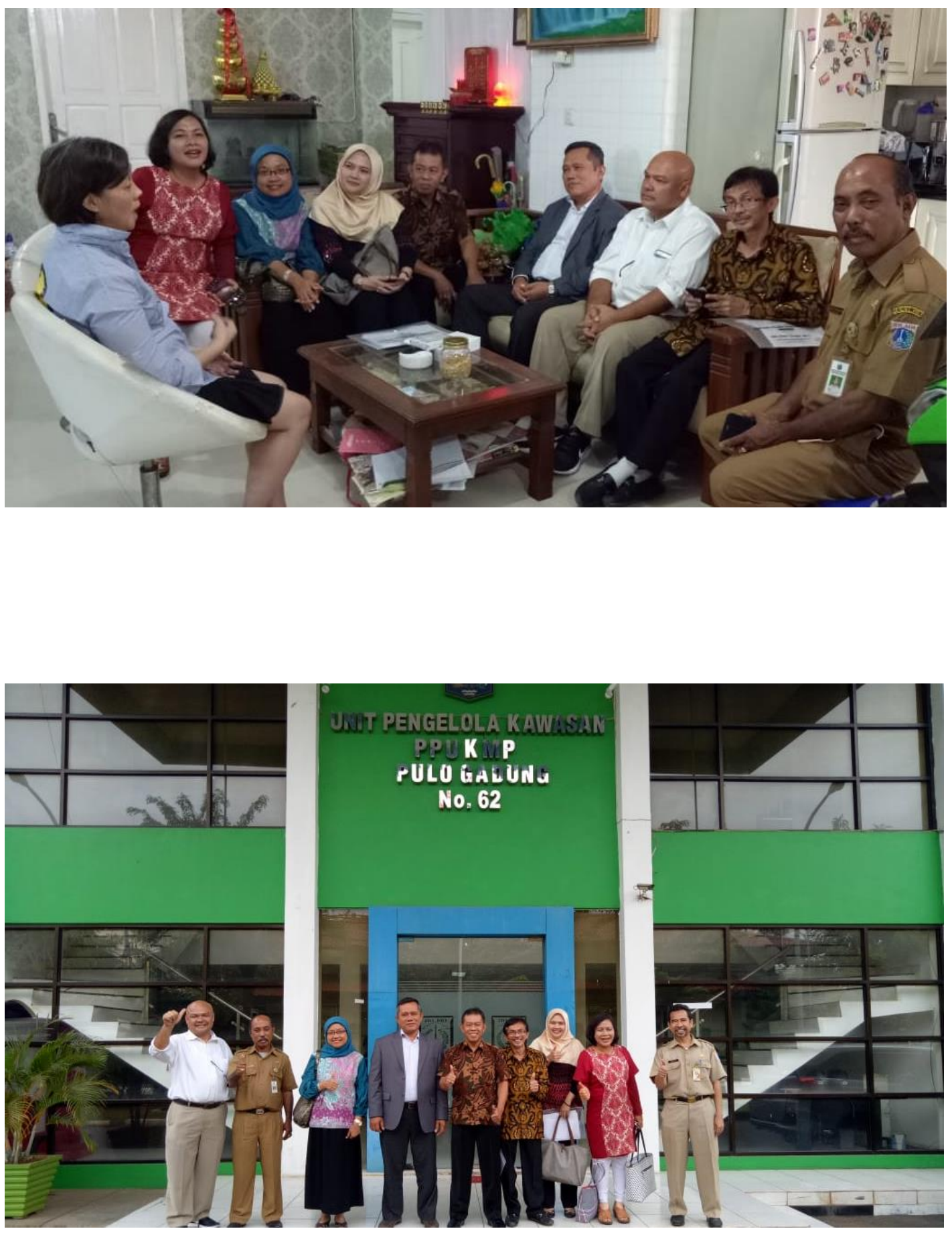